\title{
Analyses of the sucrose synthase gene family in cotton: structure, phylogeny and expression patterns
}

\author{
Aiqun Chen ${ }^{1,2}$, Shae He ${ }^{1}$, Feifei Li', Zhao Li ${ }^{1}$, Mingquan Ding ${ }^{1}$, Qingpo Liu ${ }^{1}$ and Junkang Rong ${ }^{1 *}$
}

\begin{abstract}
Background: In plants, sucrose synthase (Sus) is widely considered as a key enzyme involved in sucrose metabolism. Several paralogous genes encoding different isozymes of Sus have been identified and characterized in multiple plant genomes, while limited information of Sus genes is available to date for cotton.

Results: Here, we report the molecular cloning, structural organization, phylogenetic evolution and expression profiles of seven Sus genes (GaSus1 to 7) identified from diploid fiber cotton (Gossypium arboreum). Comparisons between cDNA and genomic sequences revealed that the cotton GaSus genes were interrupted by multiple introns. Comparative screening of introns in homologous genes demonstrated that the number and position of Sus introns are highly conserved among Sus genes in cotton and other more distantly related plant species. Phylogenetic analysis showed that GaSus1, GaSus2, GaSus3, GaSus4 and GaSus5 could be clustered together into a dicot Sus group, while GaSus6 and GaSus7 were separated evenly into other two groups, with members from both dicot and monocot species. Expression profiles analyses of the seven Sus genes indicated that except GaSus2, of which the transcripts was undetectable in all tissues examined, and GaSus7, which was only expressed in stem and petal, the other five paralogues were differentially expressed in a wide ranges of tissues, and showed developmentdependent expression profiles in cotton fiber cells.
\end{abstract}

Conclusions: This is a comprehensive study of the Sus gene family in cotton plant. The results presented in this work provide new insights into the evolutionary conservation and sub-functional divergence of the cotton Sus gene family in response to cotton fiber growth and development.

Keywords: Sucrose synthase, Gene structure, Phylogeny, Expression pattern, Cotton

\section{Background}

Sucrose is the major form of photosynthate for export from the source leaves into cellular metabolism of most plants [1]. The transfer of sucrose to the sink organs often requires its cleavage by two key enzymes: invertase (Inv), which hydrolyzes sucrose into glucose and fructose, and sucrose synthase (Sus), which is capable of catalyzing a reversible reaction but preferring to convert sucrose and UDP into fructose and UDP-glucose [2-4]. Both of the two enzymes have been demonstrated to be tightly linked with the processes of phloem unloading $[5,6]$, and the Sus has also been well characterized in

\footnotetext{
* Correspondence: jkrong@yahoo.com

${ }^{1}$ School of Agriculture and Food Science, Zhejiang A \& F University, Lin'an, Hangzhou, Zhejiang 311300, China

Full list of author information is available at the end of the article
}

various plants as playing crucial roles in regulation of carbon partitioning into various pathways that important for storage functions and metabolic structure of the plant cell $[7,8]$. For instance, Sus cleavage activity has been documented repeatedly to be highly correlated with sink strength of various starch storing organs including potato tubers, carrot roots, maize kernels and pea embryos [9-13]. Sus activity is also proposed to be responsible for cellulose synthesis, by supplying UDPglucose as substrates, which has been shown to be essential for cell wall thickening and cotton fiber cell development [14-16]. In addition, Sus activity is also considered to be associated with other important metabolic processes such as sugar import [17,18], environmental stresses response [19,20], and nitrogen fixation
Ciomed Central

(c) 2012 Chen et al.; licensee BioMed Central Ltd. This is an Open Access article distributed under the terms of the Creative Commons Attribution License (http://creativecommons.org/licenses/by/2.0), which permits unrestricted use, distribution, and reproduction in any medium, provided the original work is properly cited. 
as well as arbuscule maturation and maintenance in mycorrhizal roots of legumes [21,22].

The identification and subsequent characterization of the genes encoding plant sucrose synthase is the first step towards understanding their physiological roles and metabolic mechanism involved in different growth processes. Recent studies have revealed that Sus isozymes are encoded by a small, multigene family that comprises at least three Sus genes in the most plant species. With the completion of the genome sequence analysis, recent studies showed that model plant species, Arabidopsis and rice, both contain an Sus gene family with six distinct active Sus genes, suggesting gene expansion in higher plants during evolution [23,24]. Similarly in the model legume Lotus japonicus, at least six Sus genes are known to exist in the Sus gene family [25]. Studies on these Sus sequences and phylogenetic relatedness revealed that structural conservation and functional divergence occurred within the gene family during evolution. Members of the Sus gene family in many plant species are divergent in function and differentially expressed during plant development. For example, maize harbors a Sus family containing at least three distinct genes, Sh1, Sus1 and Sus3. Sh1 is most abundantly expressed in developing endosperm, and has the dominant role in cell wall synthesis. Sus 1 is expressed in a wide range of tissues, but plays a major role in starch synthesis [26,27]. The pea Sus gene family also includes at least three divergent members, Sus1, Sus2 and Sus3. Sus1 is ubiquitously and highly expressed in the developing seed. Sus 2 is mainly expressed in older testas and leaves, while Sus3 is weakly expressed only in flowers and young testas. Furthermore, the lack of Sus1 activity in mutant seeds and root nodules could not be compensated by Sus 2 and Sus3 [13]. Arabidopsis contains three major Sus gene classes with distinct but partially overlapping expression profiles, and the specific roles have been assigned for each gene by extensive studies of corresponding knockout mutants [20]. In other plant species, such as rice, Lotus japonicus and citrus, Sus genes have also been demonstrated to be expressed in tissue-specific and developmentdependent patterns $[24,25,28,29]$. In all cases, the differential expression of Sus genes implies that each Sus isoform may have evolved into specialized functions in different tissues. Although Sus genes in a few plant species such as Arabidopsis, have been well studied, our knowledge of cotton Sus genes, especially their evolutionary mechanisms and potential functions in fiber growth and development, needs to be well explored.

Cotton fiber is not only the world's most important textile material, but also the ideal experimental system for studying the mechanism of cell development based on its single-celled profile [30]. Cotton fiber is originated from epidermal cells of ovules, and its growth and development is a highly gene-regulated process involving four distinct, but overlapping stages: initiation, elongation, secondary wall synthesis, and maturation [31]. Many genes, including the Sus genes, have been proposed to be involved in controlling cotton fiber development [32]. Previous studies based on southern blot analysis suggested the existence of a small gene family encoding different Sus isoforms within the tetraploid upland cotton genome [33], but to date limited works to characterize these particular Sus genes have been reported, except for SS3 (GhSus3, accession no. U73588), which was isolated previously from an upland cotton fiber cDNA library and has been demonstrated to play an important role in ovule development and fiber cell initiation [34]. For the purpose of gaining a comprehensive understanding of the molecular and evolutionary characterization as well as the possible functions of cotton Sus family, it is of great necessity and significance to identify and subsequently determine the expression patterns of any members belonging to this gene family.

In the current work, we reported the identification and characterization of seven Sus genes in cotton species and investigated their expression patterns at the transcriptional level. The analysis in this study mainly focused on the gene identification, evolutionary relationship, exon/intron organization and tissue-specific expression patterns of each member of the cotton Sus gene family. Therefore, our results obtained from this study will provide a foundation and framework for the further studies to gain a comprehensive understanding of the physiological roles of each cotton Sus gene in regulating the cotton plant growth, especially for the growth and development of cotton fiber.

\section{Results}

\section{Cloning and sequence analysis of Sus cDNAs in diploid fiber cotton}

In order to identify the potential Sus homologues in cotton, comparisons between coding sequences of plant known Sus genes were performed and regions exhibiting somewhat similarities were picked out and used to design multiple pairs of degenerate primers for PCR amplification. The genomic DNA of diploid fiber cotton (G. arboreum), rather than the allotetraploid cotton species, was used as a template, to avoid the laborious analysis of allelic sequence variation within the $A_{T}$ and $D_{T}$ sub-genomes. Eventually, five distinct non-allelic genomic fragments exhibiting substantial homology to plant Sus genes were identified by massive sequencing of the PCR-generated clones. In addition, using the mRNA sequences of Arabidopsis Sus genes as queries, the cotton EST database was extensively searched, leading to the assembly of other two additional contigs as putative Sus genes. The seven newly isolated gene fragments were named as GaSus1 to 7, respectively, 
according to the naming convention for Sus genes in other plant species. 5' and 3' RACE subsequently resulted in the cloning of the full-length cDNAs of these genes, except GaSus2, of which the mRNA could not be detectable in all tissues of cotton (described later).

Molecular analysis of the full-length deduced polypeptides indicated that the putative proteins of these cotton Sus genes contain 796-824 amino acids (predicted 90.26$93.14 \mathrm{kDa}$ in molecular weight) with their isoelectric point calculated to lie between 6.26 and 7.27 (Additional File 1), similar to the molecular feature of Sus isozymes from other plant species. Additionally, all the GaSus amino acid sequences, except GaSus2, share the conserved Ser residue in the $\mathrm{N}$-terminal regions (Figure 1), which has been documented to be phosphorylated by the Ser/Thr protein kinase in maize $[35,36]$. Furthermore, using the Interproscan algorithm (http://www.ebi.ac.uk/interpro/), two conserved, sucrose synthase and the glucosyl-transferase domains, which have been suggested to be typical signatures of Sus proteins were also identified in all the cotton GaSus genes (Figure 1). These findings led to the suggestion that these newly isolated genes encode different isozymes of sucrose synthase in cotton.

Multiple sequence alignment using the DNAMAN algorithm revealed high levels of similarities between the coding sequences (CDSs) of GaSus1 to 5, within which GaSus1, GaSus3 and GaSus4 were found to be the more closely related genes, sharing much higher sequence identities (85.4-87.8\% at the nucleotide level, and 94.3$94.9 \%$ at the amino acid level), compared to the other paralogues (Table 1). Moreover, except GaSus3 had a Val/Glu deletion at the third last position of the $\mathrm{C}$ termini, there is only $3 \%$ substitution rate at amino acid level between the three proteins compared with each other (Additional File 2). The other two paralogues, GaSus6 and GaSus7, had relatively lower levels of identities when compared to GaSus1 to 5, or compared with each another (Table 1).

\section{Exon/Intron organization of the cotton Sus gene family}

Comparative analysis of the exon/intron gene structure may provide some clues for the understanding of the evolutionary mechanisms underlying the genesis of family genes. In order to investigate the exon/intron structure of the cotton GaSus genes, seven genomic DNA sequences, encompassing putative overall coding regions of GaSus1 to 7, were cloned from the $G$. arboreum genome. A comparison between the cDNA (except GaSus2) and genomic sequences, revealed that these GaSus genes are interrupted by multiple introns. As shown in Figure 2a (to highlight the exon structures, the size of exons, introns and non-coding regions were not actually presented), GaSus1, GaSus3 and GaSus7 all contain 11 introns in their coding regions (between the start and stop codons), while GaSus4 and GaSus6 are characterized by one and three more introns (12 and 14 introns, respectively) than the three paralogues. However, GaSus 5 is characterized by having only 9 introns. As the absence of the cDNA sequence, the exon/intron structure of GaSus2 was predicted online using the FGENESH algorithm (http://linux1.softberry.com/berry.phtml?topic=fgenesh \& group $=$ programs\&subgroup=gfind), which resulted in the definition of 10 putative introns within its putative coding regions. The last intron, with a length more than one kb, was predicted to be the largest intron located in the cotton Sus gene family. Comparative analysis of these introns indicated a marked greater difference in sequence similarities compared to that shown by the exons in GaSus genes (data not shown). In addition, most of the intron sizes of the seven GaSus genes range within 70-110 bp in length, except GaSus6, within which 57\% (8 of 14) introns are larger than $120 \mathrm{bp}$ in length (Figure 2a). Interestingly, the third largest intron $(648 \mathrm{bp})$ was found to locate in the $5^{\prime}$ untranslated regions (UTR) of GaSus3, and was very close ( 9 bases) to the ATG start codon. In addition, all the introns confer the GT-AG splicing rule, except for the sixth intron of GaSus7, which was spliced at the unusual GC-AG splicing sites.

Similar to the high identities shown by the alignment of amino acid sequence, high conservation of exon/intron structures could also been observed from the schematic representation of cotton Sus genes. As observed in Figure $2 b$, most of the introns are shared (located in the same position related to the position of exons) between the Sus homologues not only in cotton, and also in the phylogenetically distant species Arabidopsis and rice. Moreover, GaSus7 exhibited an extension of the last exon compared to the other GaSus genes, such feature are also observed, but more conspicuous in the Arabidopsis AtSus6 and the rice OsSus6 orthologues. Alignments of both the cDNA sequences and their predicted amino acid sequences between GaSus7, AtSus6 and OsSus6 revealed poor identities in the extended regions of the last exons, but much high identities in the other coding sequence (data not shown). Moreover, similarity searches with the BLAST algorithm against the NCBI database using the extended regions of the three orthologues failed to hit any sequence, except themselves, that showed significant similarities. In addition, careful scrutiny of the exon/intron structure in coding regions of Sus genes from two dicots (cotton and Arabidopsis) and two monocots (rice and maize) revealed that among these 21 sequences, introns were present at a total of 16 positions, in which 14 introns, in conserved positions, were observed to be contained in most of the Sus sequences from the four distantly related species, suggesting that ancestral Sus genes common to monocots and dicots contained 14 introns in these positions. The presence of an intron in the $5^{\prime}$ untranslated region of cotton GaSus3 sequence and introns 15 and 16 at novel 


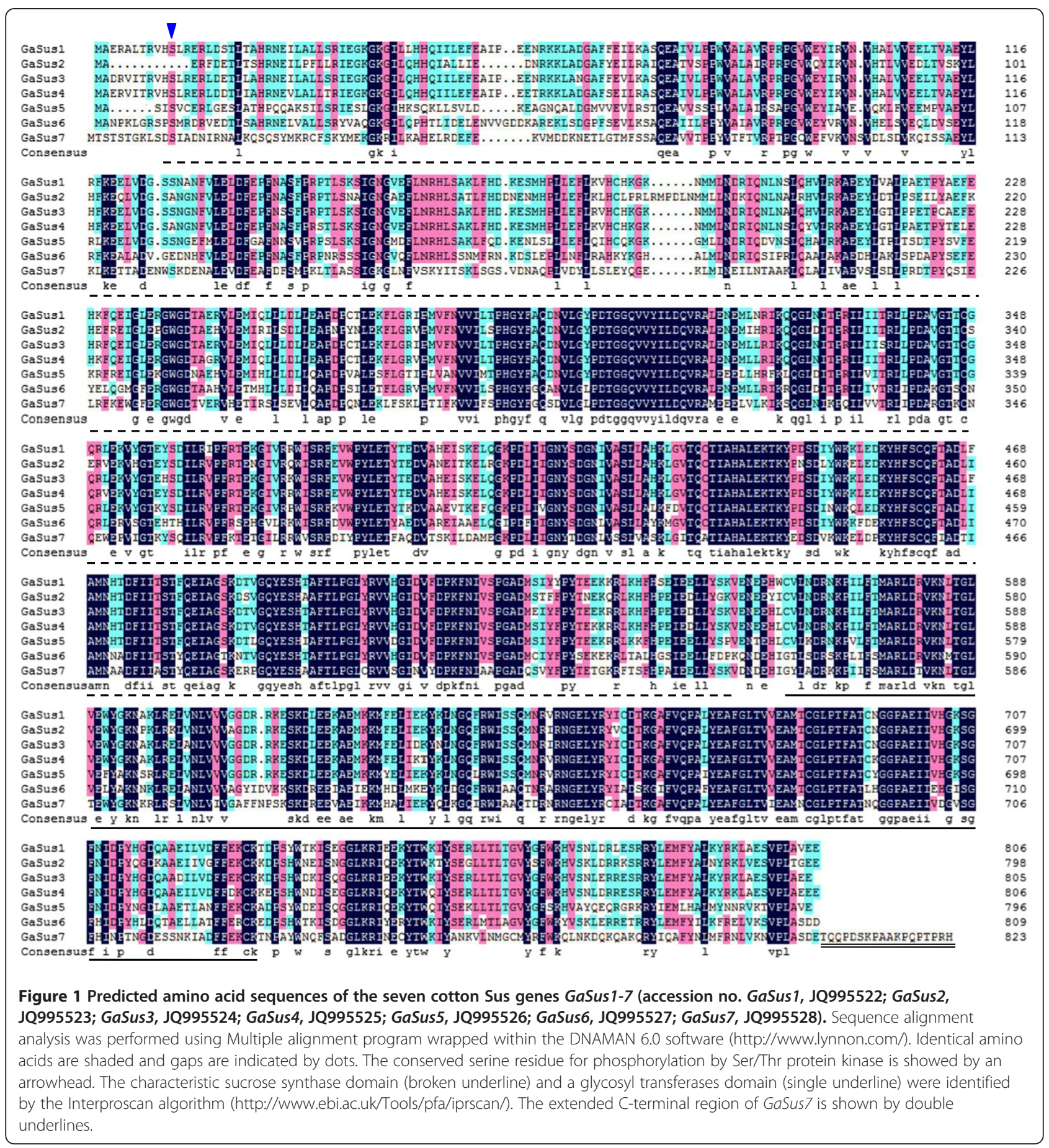

positions in the Arabidopsis AtSus5 and rice OsSus5 sequences may represent derived characters during evolution. Several of the Sus genes lack one or more introns (Figure 2a, b and Figure 3), led to the suggestion that this occurred by intron loss. Interestingly, intron loss events occurred mainly associated with the fifth, sixth and 12th introns of dicots Sus genes, resulting in the formation of relatively larger exons, such as 336, 432 and 564(567) bp- length exons in some cotton and Arabidopsis homologues.

To further investigate evolutionary conservation and sequence divergence of Sus genes among different cotton species, we also cloned the orthologues of the seven GaSus genes from other three wild diploid cotton genomes: $G$. anomalum $\left(\mathrm{B}_{1}\right)$, G. sturtianum $\left(\mathrm{C}_{1}\right)$ and G. raimondii $\left(\mathrm{D}_{5}\right)$, as well as from an outgroup species Gossyploides kirkii (K). 
Table 1 Identity matrix for the seven GaSus coding sequences and their predicted amino acid sequences

\begin{tabular}{|c|c|c|c|c|c|c|c|c|}
\hline & & & & & $\mathrm{o}$ acid ide & & & \\
\hline & & GaSus1 & GaSus2 & GaSus3 & GaSus4 & GaSus5 & GaSus6 & GaSus7 \\
\hline Nucleotide identity & GaSus1 & - & 86.1 & 94.9 & 94.4 & 77.4 & 71.2 & 55.7 \\
\hline & GaSus2 & 83.1 & - & 86.2 & 86.7 & 77.0 & 68.3 & 57.0 \\
\hline & GaSus3 & 87.1 & 83.4 & - & 94.3 & 77.1 & 71.6 & 55.0 \\
\hline & GaSus4 & 85.4 & 83.9 & 87.8 & - & 76.6 & 70.8 & 55.2 \\
\hline & GaSus5 & 74.8 & 75.0 & 75.2 & 74.5 & - & 64.3 & 55.1 \\
\hline & GaSus6 & 67.7 & 66.9 & 68.5 & 68.5 & 64.7 & - & 56.0 \\
\hline & GaSus7 & 58.5 & 59.8 & 59.2 & 58.7 & 59.0 & 59.5 & - \\
\hline
\end{tabular}

Sequence comparison and gene structure prediction of the orthologous genes from the other four diploid cotton relatives revealed identical amino acid sizes (Additional File 1), consistent exon/intron structures and very high simialities not only in coding sequences, but also in noncoding regions to the corresponding orthologs in G. arboreum (Additional File 3). Moreover, comparisons between the Sus gene sequences in the five cotton diploid species permitted the identification of several SSRs (simple sequence repeats; microsatellites) located within different introns of the orthologues of seven Sus genes (Additional File 3), which might be further used to develop SSR or intronic polymorphism markers in cotton lineages.

\section{Phylogenetic analysis of cotton Sus genes and other plant Sus homologs}

In order to carry out a comprehensive analysis of evolutionary relationships among Sus gene families between cotton and other plant species, including the seven isoforms of cotton Sus, a total of 59 plant Sus amino acid sequences, representing 17 species, were aligned with the ClustalX program and used to construct an unrooted tree for phylogenetic analysis using Neighbour-Joining method. We also performed a bootstrap analysis (1000 replicates) to determine the robustness of the phylogram's topology. The phylogenetic tree analysis revealed both relatively deep evolutionary root and the existence of more recent duplications for the Sus genes. As shown in Figure 4, three major groups of Sus proteins are inferred (for simplicity in this paper, the three groups were named as Sus I, II and III, respectively), as they are supported by high bootstrap values $>95 \%$. Genes from dicot- and monocotyledonous plants are found in all the three groups, suggesting their evolutionary divergence before the common ancestor of dicots and monocots. In addition, Sus proteins in Sus I group can be well classified into two distinct subclades, consisting of one dicot-specific Sus I group and one monocot-specific Sus I group.

The dicot Sus I group contains the proteins solely from the dicotyledonous plant species, in which they are subgrouped by phylogeny. For example, one group of solanaceous Sus proteins, including members from tomato and potato species, forms a cluster together with the two Daucus carrot proteins, DcSus1 and DcSus2. These proteins are part of the largest group that includes brassicaceous, daucus, solanaceous, leguminous, populus and citrus proteins but not a single cotton proteins. For cotton, five of the seven GaSus genes (GaSus1 to 5) fallen into this dicot group, and cluster together by forming an independent cotton clade to the exclusion of citrus, Arabidopsis, as well as other dicots genes, suggesting that a single Sus gene has expanded through independent duplication within the cotton lineages occurred after cotton separation with citrus and Arabidopsis species. Within the cotton clade, three paralogues, GaSus1, GaSus3 and GaSus4, which share a very high degree of sequence similarities, grouped more closely in the phylogenetic tree. The short branches separating the three genes suggesting that duplications that gave rise to them occurred relatively recently. In addition, GaSus5 was found to be unambiguously distant from the other four paralogues within this group. In contrast to dicot Sus I group, the monocot Sus I group thus includes members exclusively from monocot species, in which the proteins can be divided into two subclasses. Both of the subclasses contain Sus genes from rice, maize, wheat, barley and bamboo, suggesting that some ancestor Sus genes had diverged before gramineous species evolved into different plant lineages, and then underwent independent evolution within each lineage.

Unlike cotton Sus genes expanded in dicot Sus I group, the other two paralogues, GaSus6 and GaSus7, were evenly separated into the other two groups, Sus II and III, with members from both dicot and monocot species. Additionally, in these two groups, genes from dicots and monocots were not found in distinct subgroups, suggesting that the significant duplications that gave rise to Sus II and III groups should be no younger than the monocots/dicots split.

\section{Expression analysis of the cotton Sus genes at different developmental stages}

Systematic analysis of the expression patterns of Sus family genes can help to reveal their possible physiological functions involved in different growth processes 


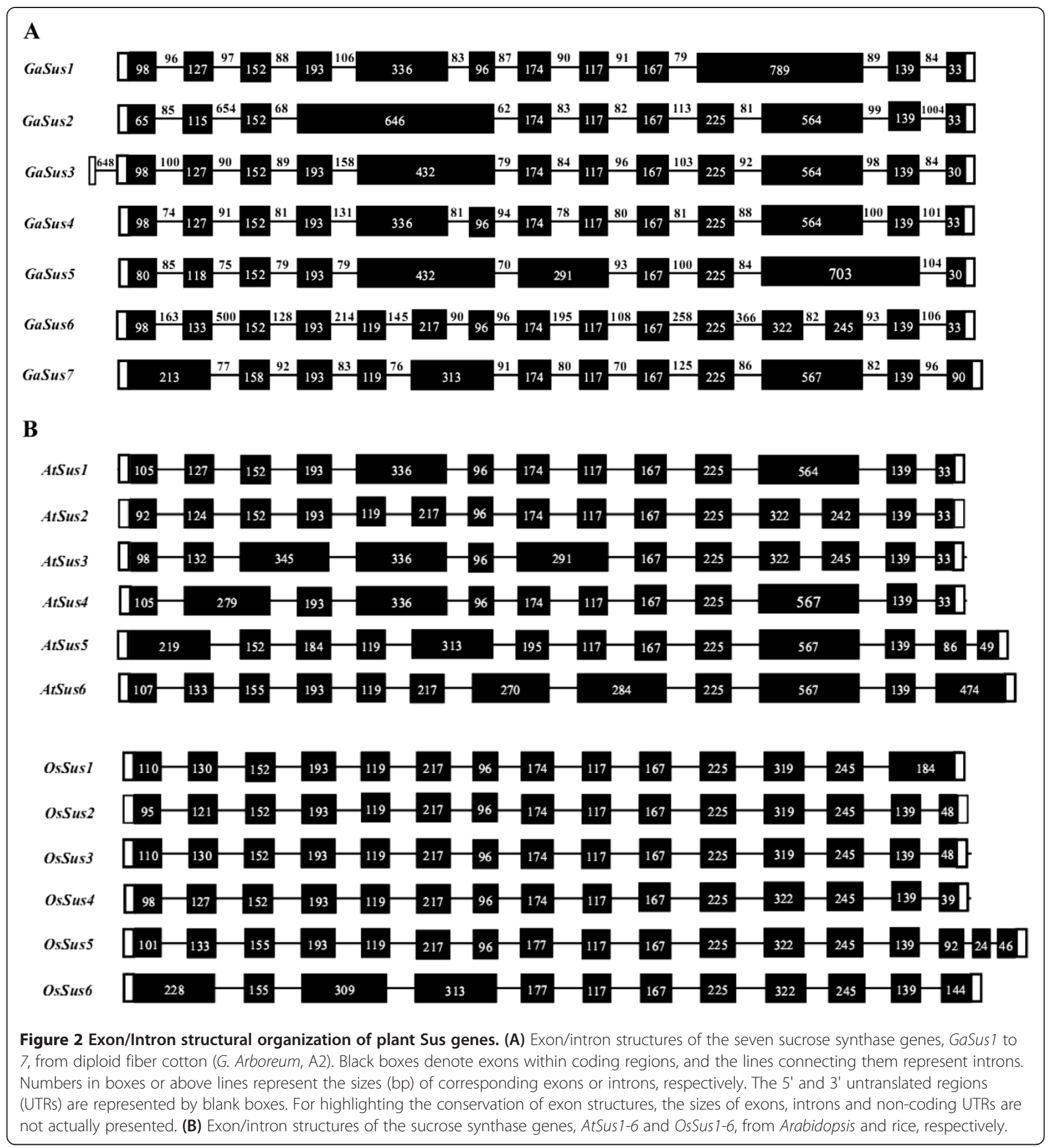

in plant. In order to better learn the potential functions of specific isoforms of Sus in cotton, the tissue-specific expression of GaSus genes were firstly examined in various cotton tissues, including roots, stems, petals and young leaves, as well as fibers at different developmental stages using semi-quantitative RT-PCR. It is worth to point out that there is a very high sequence similarity within the encoding sequence of some GaSus genes, and their reverse primers were therefore designed within their 3' untranslated regions to guarantee the primer specificity. As shown in Figure 5, except GaSus2, of which the transcripts was undetectable in all tissues examined, and GaSus7, of which the transcripts could only be detected in stem and petal, the other GaSus transcripts were detected in a wide range of tissues and showed distinct but partially overlapping expression 


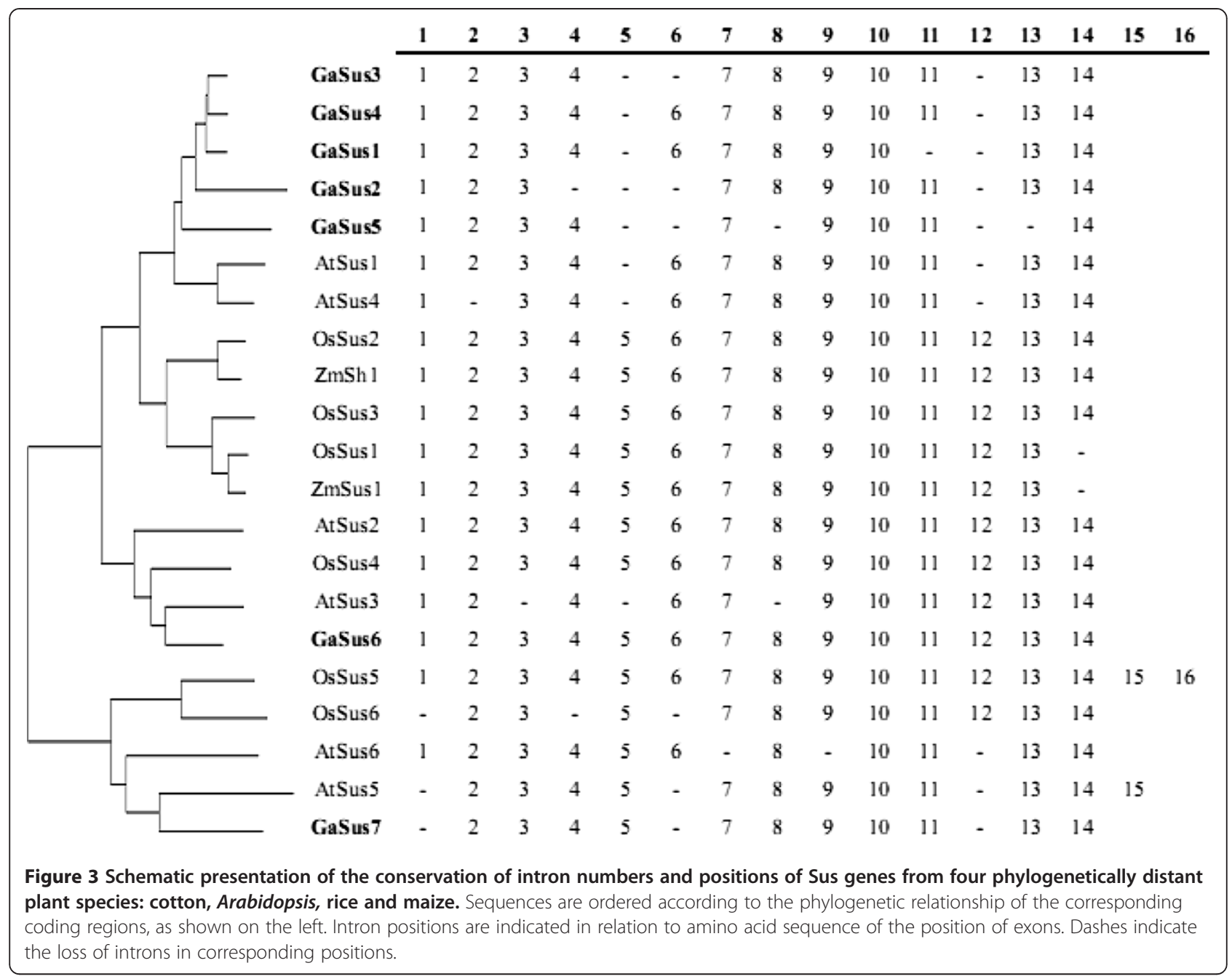

patterns, suggesting that Sus genes might be implicated in a range of physiological processes in cotton plant.

Real-time RT-PCR was further performed to quantitatively determine the relative expression level of specific GaSus gene in different tissues and in fibers at different developmental stages (Figure 6a). The quantitative results showed a similar expression profiles to those observed from semi-quantitative RT-RCR. In detail, GaSus1 was expressed highly in petal and fiber at $15 \mathrm{dpa}$, and also to some extent in stem, ovules and fibers at other developmental stages, while very slightly in roots and leaves. GaSus3 was ubiquitously expressed in all tissues, and the transcription levels were highly detected in petal, ovule at $0 \mathrm{dpa}$ and fiber at $15 \mathrm{dpa}$. In addition, the transcripts of GaSus3 in fiber were decreased as the fiber development from 0 to 10 dpa. GaSus 4 was expressed very slightly in stem, leaf and petal, and had a similar, but significant lower expression tendency in fibers at different developmental stages compared to GaSus3. The highest transcript levels for GaSus5 was also detected in fiber at $15 \mathrm{dpa}$, while very low expression levels for this gene was observed in fibers around at 0 and $5 \mathrm{dpa}$, as well as in root, leaf and petal. In addition, transcripts in fibers were continuously increasing with cotton fiber development from 5 to $15 \mathrm{dpa}$, but declining observably at $20 \mathrm{dpa}$. The expression pattern of the other two paralogues, GaSus6 and GaSus7, were highly divergent. GaSus6 was expressed in all tissues examined, but with relatively low levels in fibers. In contrast, GaSus7 showed distinct tissue-specific patterns with its transcripts were only detectable in two tissues: very weak in stems and much abundant in petals.

As it has been documented repeatedly that the activity of Sus was highly correlated to cotton seed and fiber growth and development, the relative transcription level of five fiber-related GaSus genes were therefore quantitatively compared in fiber cells at different developmental stages. As shown in Figure 6b, at fiber initiation and early elongation stages (0-10 dpa), GaSus3 was the gene that had significantly higher expression levels than other paralogues in cotton Sus family. As the fiber develops 


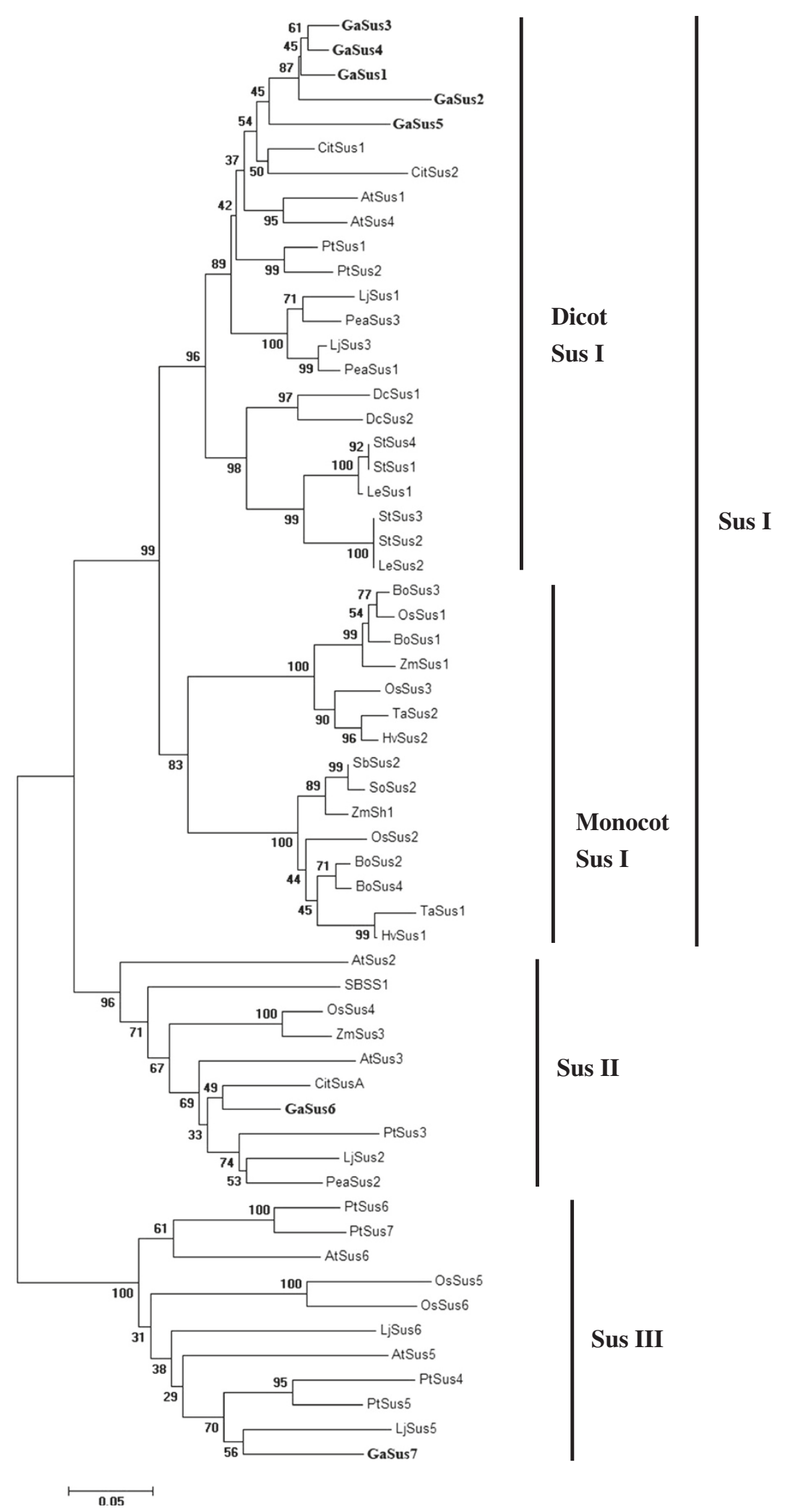

Figure 4 (See legend on next page.) 
(See figure on previous page.)

Figure 4 Phylogenetic analysis of cotton Sus genes and other plant Sus homologs. Unrooted phylogenetic tree of plant Sus proteins constructed using the neighbor-joining method with MEGA 5.0 program. Isozymes and corresponding plant species are: cotton, GaSus 1 to 7 (this study); Potato, StSus1 to 4 [9]; Pea, PeaSus1 to 3 [13]; Wheat, TaSus1 and TaSus2 [15]; Arabidopsis thaliana, AtSus1 to 6 [23]; Rice, OsSus1 to 6 [24]; Lotus japonicus, LjSus1 to 6 [25]; Citrus, CitSus1, CitSus2 and CitSusA [29]; Bamboo, BoSus1 to 4 [37]; Tomato, LeSus1 and LeSus2 [38]; Carrot, DcSus1 and DcSus2 [39]; Maize, ZmSh1, ZmSus1 and ZmSus3 [40]; Barley, HvSus1 and HvSus2 [41]; Sugarbeet, SbSS1 [42]; Sorghum, SbSus2 (accession no. FJ513325); Sugarcane, SoSus2 (accession no. AY118266); Populus, PtSus1 to 7 [43].

further from 10 to $15 \mathrm{dpa}$, GaSus5 and GaSus1 were becoming the predominant forms, contributing approximately $70 \%$ of the total amount of Sus transcripts in fiber cells. However, with the fiber develop further from 15 to $20 \mathrm{dpa}$, the dominant position of GaSus 5 was lost and replaced by GaSus1 and GaSus3.

\section{Discussion}

Recently, benefiting from the whole genome sequencing of model plants, dozens of genes encoding Sus isozymes have been identified from various plant species using the comparative genome approaches. Typically, the complete genomic sequence of the model species Arabidopsis and rice allows revealing a total of six Sus genes in each of the two plants, representing the entire Sus gene members of two groups of flowering plants, dicots and monocots. Although the exact number of Sus genes in most of other plants could not be reliably evaluated due to the incomplete coverage of genome sequencing, cotton, however, appears to have more distinct Sus genes than Arabidopsis and rice. Previously four distinct genes encoding different types of cotton Sus isoforms, SusA (GhSus3, accession no. U73588), SusB, SusC and SusD, had been identified in the tetraploid upland cotton species [44]. Our present work through molecular cloning and database searching brings the number of presently known members of cotton Sus gene family to at least seven, comprising one of the largest Sus gene families described thus far. Given the limited knowledge of cotton Sus gene family for us to data, further investigation of their evolutionary relationships, molecular structures, as well as their expression patterns therefore becomes an important step towards comprehensive understanding their molecular mechanism and possible functions involved in different growth processes in cotton.

\section{Evolutionary conservation and divergence of cotton Sus genes}

Although the evolution of multigene families involves multiple mechanisms, comprehensive analysis of phylogenetic tree and exon/intron gene structures, to a certain extent, allow us to make some generalizations and predictions about the possible origin of and relationships between different isoforms of Sus, as well as their possible function. Plant Sus proteins have been historically divided into at least three major groups (Sus1, SusA and New Group/NG) on the basis of phylogenetic tree and

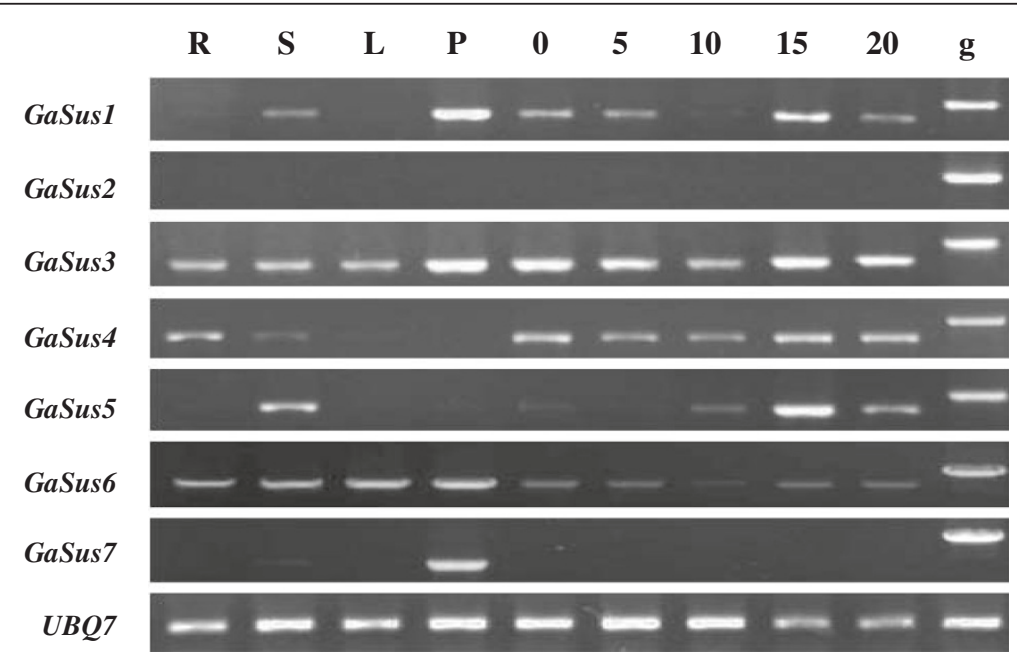

Figure 5 Semiquantitative RT-PCR analysis of the seven GaSus genes in cotton plants (G. arboreum, A2). The RNA were prepared from different tissues and over fiber development: root (R), stem (S), young leaf (L), petal (P), ovule at 0 dpa (day post anthesis) and fiber samples from bolls at 5, 10, 15, and 20 dpa. Primers specific to the seven GaSus were used, and the PCR products amplified from genomic DNA (g) containing at least one introns were taken as controls to exclude any DNA contamination. A constitutive ubiquitin gene (UBQ7, accession no. DQ116441) was used as an internal control to normalize differences in template concentrations. 

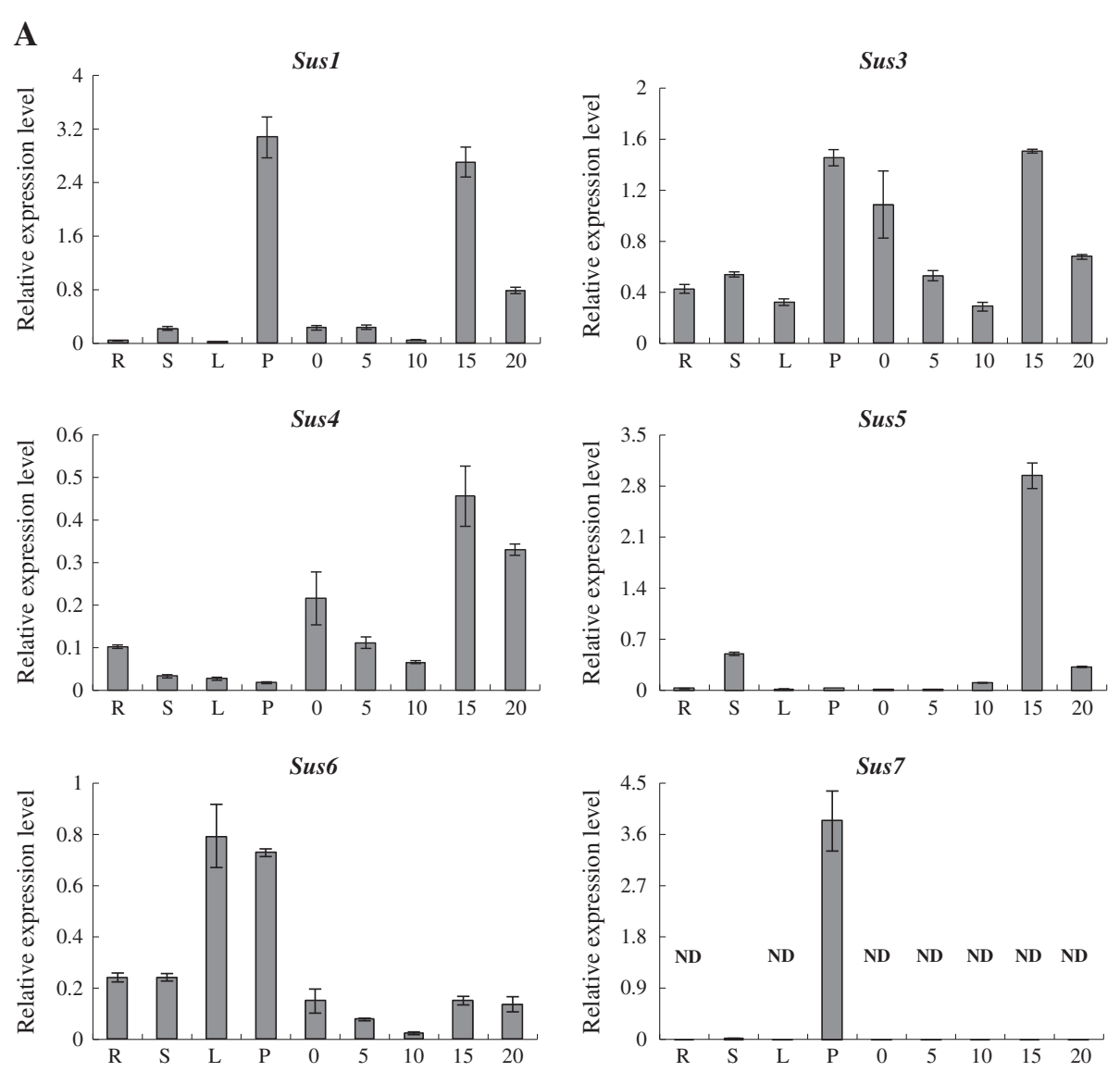

$\mathbf{B}$

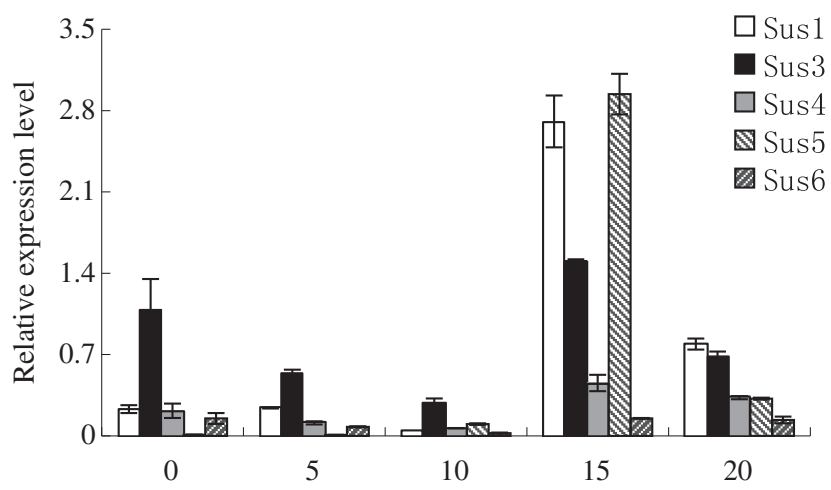

Figure 6 Real-time RT-PCR analysis of GaSus genes in different cotton tissues. (A) Relative value of GaSus gene expression in cotton tissues, including root (R), stem (S), young leaves (L), petal (P), ovule at $0 \mathrm{dpa}$ (day post anthesis) and fiber samples from bolls at 5, 10, 15, and 20 dpa, was shown as percentage of GaUBQ7 expression activity (see Methods). ND indicates that transcripts were not detectable. (B) Relative expression level of five fiber-developmental related cotton GaSus genes at different fiber developmental stages.

molecular structures analysis of their sequences [24,29]. Phylogenetic analysis of cotton GaSus genes and other plant homologues in our work corroborated this classification (for unification and simplification, in this study, we renamed them as Sus I, II and III, respectively), and further support the idea that higher plant species may have at least one gene for each of the three groups [24].
The presence of five cotton Sus genes, GaSus1 to 5, in the Sus I group that cluster together with other dicot genes and separately from multiple monocot Sus genes is the direct evidence of that multiple gene duplication events occurred after the monocot/dicot divergence both within dicots and monocots, giving rise to two subclades: dicot-specific Sus I group and the monocot- 
specific Sus I group. As the five cotton genes group together to the exclusion of citrus, Arabidopsis and other dicot homologues in our phylogenetic tree, it is suggestive of that gene duplication events that gave rise to the five cotton Sus genes occurred after the separation of cotton/citrus/Arabidopsis from a common ancestor. The presence of one cotton Sus gene in each of the other two groups, Sus II and III, with members from both dicot and monocot species, indicating that Sus II and III groups containing GaSus6 and GaSus7 are evolutionarily older than dicot Sus I group containing GaSus1 to 5 .

It has been well demonstrated in many duplicated gene families that exon structure in homologues genes may even be conserved despite low sequence conservation [45]. Differences in exon/intron structures, created by intron deletions, insertions or both events, between paralogues therefore could be used, to some extent, to estimate the evolutionary history of gene families [46]. In the present work, comparative screening of introns in homologous genes indeed revealed that the number and position of introns are highly conserved among Sus genes in cotton and other more distantly related monocot plant species (Figure 2a, b and Figure 3). As the majority of Sus sequences in the three Sus groups contain 14 introns, in conserved positions, it is tempting to speculate that the gene duplications to arise three progenitors of Sus genes, each containing 14 introns in conserved positions, occurred early in the evolution of angiosperms and predated the divergence of monocots and dicots as many of the other gene families [47]. Interestingly, although the evolution of intron is considered to be under a low selection pressure compared to exon sequences, it seems that Sus genes in monocots tend to retain more introns than in dicots, such a case occurred particularly apparently in the Sus I group, in which members from dicot cotton and Arabidopsis, without exception, have lost introns 5 and 12. Since that members from other dicots, such as Leguminosae Lotus japonicus and Rutaceae citrus, of this group also have lost the two introns [24,29], it thus led to the inference that at least twice rounds of intron loss events have occurred in the evolution of the dicot Sus genes related to Sus I group including the five cotton Sus paralogues (GaSus1 to 5), one relatively earlier event of concerted intron loss of introns 5 and 12 occurred immediately after the dicot/monocot split but predated the separation of cotton and most of the other dicots. After this event, independent events of intron loss of introns 2, 4, 6, 11 and 13 occurred related to different dicots members in Sus I group. A comparison of the number and density of introns in the gene structures of the five cotton paralogues belong to the Sus I group further demonstrated that GaSus5 was produced from relatively more ancient duplications in comparison with its three paralogues GaSus1, GaSus3 and GaSus4. Intriguingly, although Sus II group is thought to be evolutionarily older than dicot Sus I group, members in Sus II group appear to have underwent a relatively slower evolutionary rate, since that exon/intron structures of dicot genes (including cotton GaSus6) in this group have greater similarity to those of monocot Sus genes and also to the putative ancestral Sus genes (Figure 3). The most remarkable feature of the Sus III group is that members, whether from dicots or monocots, without exception, exhibit a 3' extension resulting in either a longer (AtSus6, OsSus6 and GaSus7) or additional exons (AtSus5, LjSus6 and OsSus5) in their 3' regions, it is tempting to speculate that a sequence with at least two introns had been introduced to the 3 ' region of the progenitor of Sus III group probably by an ectopic recombination that occurred before the monocots/dicots splits. The absence of commonalities on sequence and exon/intron structure in the extended regions among different members may be due to that the extended region did not involve in the definition of the protein activity of Sus (Figure 1) and thus suffered a low selection pressure during evolution. As the cotton GaSus7 have an exon/intron structure similar to the Arabidopsis AtSus5 (except AtSus5 have an additional intron and exon in its extended 3 ' region), confirming that AtSus5, but not AtSus6, is the orthologuous gene of cotton GaSus7. This is also indicative of that the loss of intron 1, 6 and 12 from cotton GaSus7 were the events that occurred before the separation of cotton and Arabidopsis lineages.

Synthesizing what we have learned from the phylogenetic tree analysis and exon/intron structure comparison, we proposed the following sequence of events to account for the evolution of the cotton Sus gene family. The first relatively earlier event that occurred before the split of monocots and dicots led to the duplication of an ancestral gene containing 14 introns to progenitors of Sus6 and Sus7. A second duplication that occurred also predated the monocots/dicots split was associated with the arising of the precursor of Sus1 to 5. Following the divergence from a common ancestor of citrus and Arabidopsis, a duplication occurred in cotton lineages and giving rise to Sus5, which subsequently underwent independent evolution and retained as a single gene, while its duplicate has expanded into four paralogues (Sus1 to 4), among which, GaSus3 and GaSus4 were produced from the most recent duplication events and consequently became the closest related genes in cotton Sus family, their closeness is well reflected in the terminal subgroups of the phylogenetic tree (Figure 4). Therefore, it might be unsurprising that GaSus4 would have a tissue-expression pattern or physiological functions similar to that of GaSus3 in cotton. GaSus2, however, seemingly have underwent a more rapid evolutionary rate and thus have a relatively longer separating branch and lower degree of sequence identity compared with the other three paralogues. It's interesting to note that 
there are only two Arabidopsis genes in the Sus I group, although Arabidopsis lineage had underwent one round of whole genome duplication since it split from a common ancestor shared with cotton [48]. The discrepancy of Sus gene numbers in related species well supports the theory that genome duplication as well as the following gene loss (diploidization) are prevalent features of plant genomes [49].

It should be emphasized that, although our efforts in this study, though molecular cloning, massive sequencing and database hunting, have brought the cotton Sus gene family to be one of the largest Sus family described to date, we could not completely exclude other paralogues for each of the three groups which might be present in the cotton species. The presence of only one cotton Sus member, compared with both Arabidopsis and Lotus japonicus having two members, in each of the Sus II and III groups in our phylogenetic tree also implies the possibility of additional, unidentified cotton Sus paralogues existent within the two groups. The topology of the phylogenetic tree in future might have some deviation in the order of evolutionary distances for different members of cotton Sus family. Therefore, more information, especially the chromosomal distribution of these cotton Sus genes, is needed to determine a more precise evolutionary relatedness among these cotton Sus genes. Although this study focused mainly on Sus genes in cotton species, the examined relative high conservation of the orthologous genes of Sus family in different cotton interspecies may lend strong evidence to support the further comparative genomics analysis across the entire family of Malvaceae.

\section{Functional divergence of the cotton GaSus gene family}

It has been well recognized that gene duplication followed by functional diversity (evolutionary changes in expression patterns and/or protein property) has played a crucial role in driving evolutionary novelty that allow organisms to differentiate new organs or increase fitness to new environments [50,51]. To data, although the functions of a few individual isoforms of Sus have been characterized in tetraploid cotton plants [52], there is no systematic functional analysis of expression patterns for different groups of diploid cotton Sus gene family.

In this study, we demonstrated that differential expression of the Sus genes occurs in cotton, as did the members of this Sus family in several other plant species, such as Arabidopsis [20,23], rice [24], Lotus japonicus [25], citrus [29], and Bamboo [37]. The differential expression profiles may suggest that Sus is implicated in a range of physiological processes in the cotton plant. The specialized expressions of Sus genes may also reflect the divergent evolution of Sus gene regulatory elements that are required for controlling the development of particular cells or tissue types during cotton plant growth [53].
Previous studies, based on the analysis of mutant and/ or transgenic plants with reduced Sus activity, have demonstrated that cotton fiber and seed development are significantly correlative to the changes of Sus activity in ovule epidermis and endosperm [34,54]. The transcription data presented here indeed provide direct evidence for strong expression of some GaSus genes in cotton ovules and fibers (Figures 5, 6a, b). The relatively high expression level of Sus genes coincident with the initiation and elongation of the fiber cell well supports the standpoint that Sus in cotton plays a pivotal role in cotton fiber growth and development. Apparently, development-dependent regulation on Sus genes, involved in cell initiation and elongation during cotton ovule and fiber development had evolved. This is typically shown by the expression of GaSus3 and GaSus5. Transcriptional analysis revealed that the GaSus3 had significantly higher expression levels in 0 dpa ovules and early developing fibers compared to the other paralogues in cotton, and displayed gradually decreasing expression levels in fibers from 0 to $10 \mathrm{dpa}$, suggesting that GaSus3 may play a major role in the early stages of fiber development, particularly in fiber initiation and early elongation. The hypothesis is indirectly supported by the previous study that suppression of the expression of GhSus3 (U73588), an orthologous gene of GaSus3, in tetraploid upland cotton, repressed cotton early seed development, fiber cell initiation and elongation. In contrast to GaSus3 expression, the transcripts of GaSus5 were very low at 0 and $5 \mathrm{dpa}$, but increased continuously in abundance and reach its highest level in fibers around at $15 \mathrm{dpa}$, and then a significant decrease as the fiber cells developed further, suggesting that GaSus5 may primarily participated in fiber cell elongation and primary cell wall synthesis. The differential, complementary expression profiles of GaSus3 and GaSus5 is the direct evidence of that specialized GaSus genes might have been evolved to meet the requirement of the carbohydrates for cellulose synthesis, fiber cell initiation and elongation during cotton fiber development. Interestingly to note, of the seven cotton Sus genes, GaSus 7 is not only the oldest duplicated gene, but also is the only one which is transcriptionally active, but not expressed in ovule and fiber cells. The strong transcription level of GaSus7 in petal implies that GaSus 7 may be primarily involved in the regulation of floral organs, but not the ovules and fibers development in cotton. As GaSus6, another old duplicated gene, is also lowly activated in cotton fiber cells compared to those relatively recent duplicated paralogues, such as GaSus1 and GaSus3 (Figures 6a, b), it is tempting to speculate that the recent duplications of Sus genes may be important or highly correlate to the cotton fiber cell differentiate. 7This might also be one of the reasonable explanations why cotton could retain more 
duplicated genes in the Sus I group than most of the other phylogenetic related species, such as Arabidopsis.

Previous studies have demonstrated that Sus expression was much heterogeneity among cotton ovule epidermal cells [54,55]. Seemingly, only those with high levels of Sus transcripts could actually differentiate into long fibers, while cells with lower or undetectable levels exhibited smaller or even no initiation out of the ovule epidermis. Transcriptional analysis of a fiberless cotton mutant sma-4 [56] in this study, however, did not show significant difference of mRNA levels in ovules at 0 dpa for all the seven Sus genes compared to the wild-type plants (Figure 7). This finding was contradictory to the earlier study on another fiberless cotton mutant $f l s$, which had no signal for Sus mRNA and protein in the ovule epidermal cells at $0 \mathrm{dpa}$, while the wide type showed strong Sus mRNA signals [54]. Such results suggested that the regulatory network leading to cotton fiber growth and development could well be more subtle and complex, and multiple genes, upstream/downstream of the Sus genes, might also have been evolved into strict controlling of cotton fiber cell initiation and elongation [57].

It is worth noting that although GaSus3 was ubiquitously expressed in the cotton plants, knock down of the Sus3

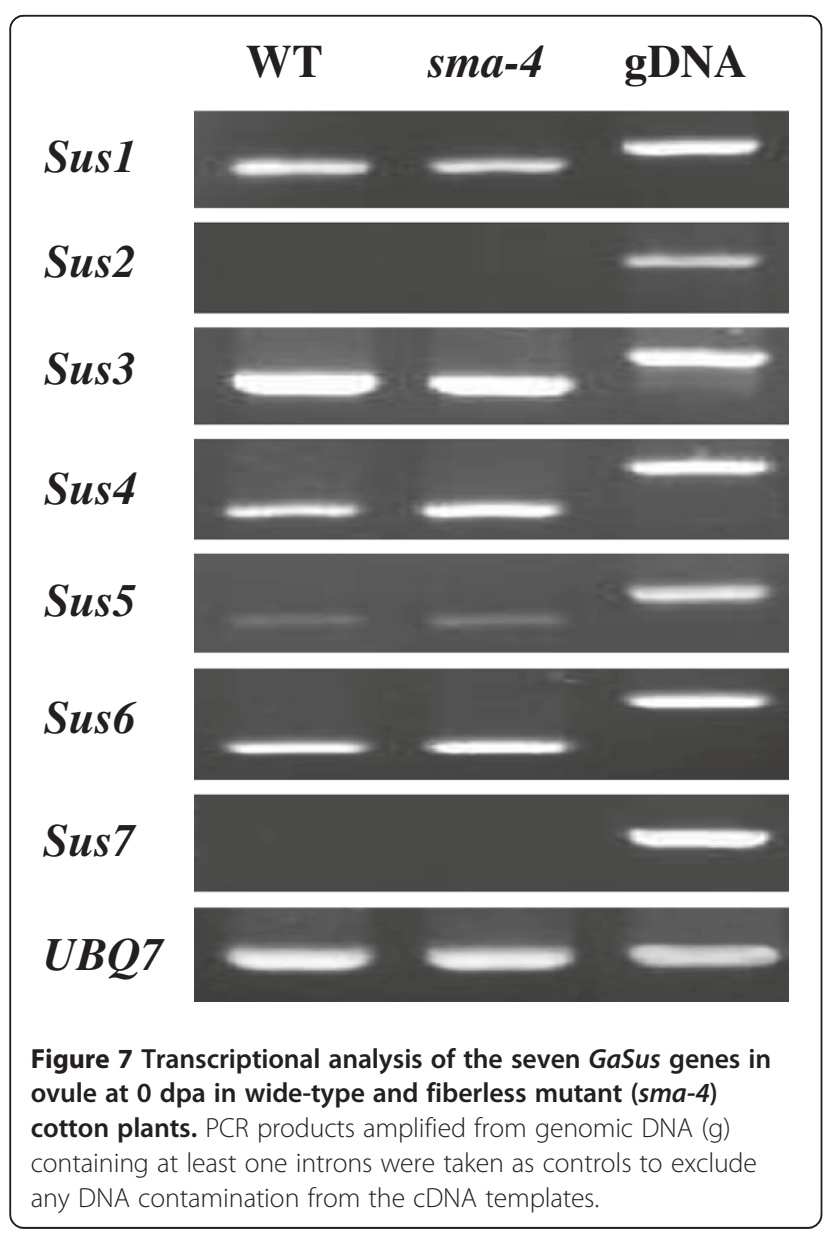

expression in upland cotton virtually unaffected vegetative growth and flowering in most of the transgenic cotton plants [34], suggesting possible functional redundancies within the cotton Sus gene family. This might be true as a result of that similar or overlapping expression pattern to the GaSus3 genes were also observed in the case of GaSus4, as well as in other paralogues in cotton. Similar results and conclusion were also obtained from the study on Arabidopsis Sus mutants that lacking individual isoforms of Sus failed to cause obvious growth phenotypes compared to the wide type of Arabidopsis plants [20], suggesting that redundancy within Sus gene family would ensure that sucrose metabolisms in particular cells or organs will be relatively insensitive to mutations and evolutionary robust.

One of the most common fate of gene duplications is thought to be elimination of one of the duplicate pair [58]. The undetectable expression of GaSus2 in all the tissues examined and its relatively faster evolutionary rate compared to the other paralogues led to the suggestion that GaSus2 may be a pseudogene or is on the way to become a pseudogene. The loss of some peptides including the conserved, functional Ser phosphorylation site (Figure 1) in the N-terminal region of the GaSus2 deduced polypeptides is also the indirect evidence that supports the hypothesis. Similarly in rice, a putative Sus gene fragment identified in the genome database searches, is also inactive and probably as a consequence of the loss of some exons and inclusion of multiple stop codons within its putative coding region [24]. Such cases were also found in some other multiple gene families, for example, the Arabidopsis actin gene family contains 10 distinct members, of which eight are functional genes and two are pseudogenes $[59,60]$.

\section{Conclusions}

This study provides the first comprehensive evaluation of the evolutionary genesis, phylogenetic relationships, exon/ intron structure organization, and tissue-expression pattern of each member of the Sus gene family in cotton species. The results presented here could offer an useful foundation and framework for future research work on understanding the potential physiological roles for each cotton Sus gene and the evolution of Sus gene family in response to sucrose metabolism during cotton fiber development, as well as the structure-function relatedness between the members of cotton Sus gene family. We also realize that the different Sus genes in cotton might play different roles in regulating sucrose metabolism and fiber development, as well as possible functional interactions or even redundancies. Such functional expectations need to be experimentally verified by characterizing the spatio-temporal expression dissection, Sus enzyme activity assay and knockout/knockdown mutants of these Sus genes in the near future. 


\section{Methods}

\section{Plant material and growth conditions}

G. arboreum (acc. $\mathrm{A}_{2}-47$ ), which was obtained from USDA collection through Dr. Peng Chee (University of Georgia, UGA), was used in this study for cloning Sus genes and gene expression analysis. The seeds were delinted, germinated and maintained in pot culture under natural conditions for three weeks, and then the plantlets were either harvested for collecting the roots, stems and leaves samples or transplanted to open field for continuing growing. For analysis of Sus gene expression during cotton fiber development, each flower was tagged on the day of flowering and were taken as $0 \mathrm{dpa}$ (days post anthesis). Developing ovules were subsequently harvested at various developmental stages from 0 to 20 days after flowering, and fibers were carefully scraped from the epidermis of the ovules. The collected samples were immediately frozen in liquid nitrogen and stored at $-80^{\circ} \mathrm{C}$ for subsequent RNA isolation.

Except G. arboreum, DNAs used for gene structure deduction and phylogenetic analysis were from G. anomalum (B1) and G. sturtianum (C1) obtained from Dr Xinlian Shen (Jiangsu Academy of Agricultural Sciences, China), and G. raimondii (D5) and Gossyploides kirkii (K) provided kindly by Dr. Andrew Paterson (UGA), here Gossypioides kirkii was used as an our group species.

\section{Cloning of Sus genes in diploid cotton of G. arboreum}

Based on the sequences of plant sucrose synthase genes accessioned in GenBank, we designed multiple pairs of degenerate primers from the conserved regions for using to amplify the homologs in diploid fiber cotton (G. arboreum). The PCR products obtained from both cDNA and genomic DNA amplification were cloned into the pMD19-T cloning vector (TaKaRa Biotechnology, Dalian, China), and then transformed into E.coli cells (DH5 $\alpha$ ) for massive sequencing. The obtained sequences were submitted to NCBI database for blast analysis. In addition, the cotton EST database were also searched using Arabidopsis Sus genes as queries to identify putative unidentified members belong to the cotton Sus gene family.

The full-length cDNAs of the cotton Sus genes were obtained using the RLM-RACE approaches (FirstChoiceRLM-RACE Kit, Ambion, USA). Approximately one and $10 \mu \mathrm{g}$ high-quality total RNA were used respectively for the $3^{\prime}$ and $5^{\prime}$ RLM-RACE protocols, strictly following the manufacturer's instructions.

\section{Phylogenetic and gene structure analysis}

The sequence data used in this study were collected using the keyword "sucrose synthase" and a query search in the GenBank using the known Sus gene sequences from cotton and Arabidopsis. Multiple alignment of the nucleotide and deduced amino acid sequences were performed using the programs ClustalX (version 1.8) [61], and DNAMAN (version 6.0)(http://www.lynnon.com/) with default gap penalties. A phylogenetic tree was constructed from amino acid sequences of deduced Sus proteins by neighbor-joining algorithms wrapped in the MEGA 5.0 phylogeny program (www.megasoftware.net).

Exon/intron structures analysis of the target Sus genes were either conducted by comparing the cDNA sequences and their genomic DNA sequences or predicted online using the FGENESH algorithm (http://linux1.softberry.com/berry. phtml?topic=fgenesh\&group=programs\&subgroup=gfind). Predicted conserved domains were screened within the deduced amino acid sequences of corresponding Sus genes using the interproscan algorithm web server (http://www. ebi.ac.uk/Tools/pfa/iprscan/).

\section{DNA and RNA extraction}

Genomic DNA was isolated from young cotton leaves using a CTAB method as described previously [62]. Total RNA was isolated from various tissue samples using the CTAB-sour phenol extraction method as described by Jiang et al., [63]. RNA samples were treated with DNase I (TaKaRa) after the extraction to eliminate the trace contaminants of genomic DNA.

\section{CDNA preparation and semiquantitative RT-PCR analysis}

For conducting reverse transcription (RT)-PCR analysis, approximately two micrograms of DNA-free total RNA from each sample was used to synthesize first-strand cDNA in a $20-\mu \mathrm{l}$ reaction solution using a M-MLV reverse transcription kit (TaKaRa), and the synthesized cDNAs were used as templates in the following RT-PCR reactions.

For each target Sus gene, PCR amplification was performed using Takara Taq polymerase with specific primer pairs listed in Additional File 4. The PCR was conducted in a heated-lid thermalcycler (Eppendorf, Germany) by following procedure: pre-denaturation at $95^{\circ} \mathrm{C}$ for $3 \mathrm{~min}$, followed by $28-30$ cycles of $30 \mathrm{~s}$ at $94^{\circ} \mathrm{C}, 60 \mathrm{~s}$ at a specific annealing temperature at $52-55^{\circ} \mathrm{C}$ for each gene, and $90 \mathrm{~s}$ at $72^{\circ} \mathrm{C}$. A cotton constitutive gene, $U B Q 7$, was used as an internal standard to adjust the relative quantity of the cDNA of each sample used in the RT-PCR analysis.

Table 2 Gene-specific primers used for real-time RT-PCR amplification

\begin{tabular}{lll}
\hline Gene & Forward primer & Reverse primer \\
\hline GaSus1 & acgggttctggaagcatgtgtc & ccccggcaacttcaatttcaat \\
GaSus3 & cgccgtgagagtcgtcgttacc & ccaagaaaaccggcccaatg \\
GaSus4 & gccgccgttacctggagatgt & cccgcctcttcctttgttttac \\
GaSus5 & cggccaatacgagagtcacatc & cggcttgttgcggtctttag \\
GaSus6 & ggctgatgacattggctggagta & cgcaatcaaccagacccttaaat \\
GaSus7 & cgcgtttcgacatttatccttatc & tgcgcaatcgtagcctgtgtt \\
UBQ7 & gaaggcattccacctgaccaac & cttgaccttcttcttcttgtgcttg \\
\hline
\end{tabular}


To confirm the specificity of each primer and also to exclude any genomic contamination in PCR amplification, each of the target genes was also amplified with the same PCR procedures from the genomic DNA, which contains at least one intron in its amplified products. The amplified fragments were examined by electrophoresis on a $1.5-2.0 \%(\mathrm{w} / \mathrm{v})$ agarose gel and visualized by ethidium bromide (EB) staining.

\section{Quantitative real-time RT-PCR (qRT-PCR)}

Real-time quantitative RT-PCR was performed to relatively quantify the transcription levels of cotton Sus genes expressed in fibers at different developmental stages. The cDNAs used for detecting gene expression were the same as those used for semiquantitative RT-PCR analysis. The reaction was conducted on the Applied Biosystems 7300 Real-Time PCR System using the SYBER premix ExTaq kit (TaKaRa) according to the Manufacturer's instructions. The amplification of the target Sus genes was monitored by SYBR-Green fluorescence signal every cycle. The Ct (cycle threshold) value, which was defined as the PCR cycle at which a significant increase of reporter florescence signal is detected instantly, was used as a measure for the starting copy numbers of the target Sus gene. Relative quantitation for expression level of each GaSus gene was standardized to the expression level of the cotton constitutive $U B Q 7$ gene, calculated by the formula $\mathrm{Y}=10^{-(\Delta \mathrm{Ct} / 3)}$ ( $\triangle \mathrm{Ct}$ is the differences of Ct between the target Sus and the control UBQ7 products; $\left.\Delta \mathrm{Ct}=\mathrm{Ct}_{\mathrm{GaSus}}-\mathrm{Ct}_{\mathrm{UBQ}}\right)$. The specificity of primers designed for real-time RT-PCR (Table 2) was confirmed by running products on agarose gels and by sequencing after the PCR reaction. The detailed protocol of the quantitative analyses was described by Li et al., [60].

\section{Additional files}

Additional file 1: Amino acid sequences analysis of the cotton Sus genes.

Additional file 2: Multiple alignment of the amino acid sequences between three Sus genes GaSus1, GaSus3 and GaSus4.

Additional file 3: Multiple alignment of the DNA sequence between five orthologs of Sus7 cloned from four diploid cotton species $G$. arboreum (A2, GaSus7), G. anomalum (B1, GbSus7), G. sturtianum (C1, GcSus7) and G. raimondii (D5, GdSus7) and one outgroup species, Gossypioides kirkii (K, GkSus7). Corresponding regions shaded in colours represent sequence identities between these orthologous genes. The exon sequence is shown by single underline, and the intron sequences are shown by double underlines. The arrows upon the first intron sequence indicate the unusual GC/AG splicing sites in the Sus7 genes. The SSRs (simple sequence repeats; microsatellites) in the five orthologs are boxed and shaded.

Additional file 4: Gene-specific primers used for semi-quantitative RT-PCR amplification. The numbers out and in parentheses represent expected size of PCR products amplified from CDNA and genomic DNA, respectively.

\section{Abbreviations}

Sus: Sucrose synthase; EST: Expressed sequence tag; dpa: Days post anthesis.

\section{Competing interests}

The authors declare that they have no competing interests.

\section{Authors' contributions}

AQC and JKR contributed to the experimental design and manuscript drafting. QPL contributed to the manuscript editing. AQC, SEH and ZL performed the primer design, Sus gene cloning and RT-PCR validation. FFL, MQD and QPL performed the RNA extraction and bioinformatics analysis. All authors have read and approved the final manuscript.

\section{Acknowledgements}

We thank Dr. Andrew Paterson from the University of Georgia and Dr. Xinlian Shen from Jiangsu Academy of Agricultural Sciences for kindly supplying the genomic DNA of four wild diploid cotton species: G. roimondii (D5), Gossypioides kirkii (K), G. anomalum (B1) and G. sturtianum (C1). We also thank Dr. Haibao Tang from the J. Craig Venter Institute and Dr. Guiliang Tang from the Michigan Technological University for valuable comments on the manuscript revision. This work was supported by the Genetically Modified Organisms Breeding Major Projects (2009ZX05009-028B), National Natural Science Foundation of China (31100878), Natural Science Foundation of Zhejiang province (ZJNSF, Y3100407), Zhejiang Qianjiang Talent Plan (2010R10089) and Initial Foundation of ZAFU (2009FR075) to AQ Chen and (2010FR042) to JK Rong.

\section{Author details}

'School of Agriculture and Food Science, Zhejiang A \& F University, Lin'an, Hangzhou, Zhejiang 311300, China. 'State Key Laboratory of Crop Genetics and Germplasm Enhancement, College of Resources and Environmental Sciences, Nanjing Agricultural University, Nanjing 210095, China.

Received: 10 February 2012 Accepted: 16 May 2012

Published: 13 June 2012

\section{References}

1. Lutfiyya LL, Xu NF, D' Ordine RL, Morrell JA, Miller PW, Duff SMG: Phylogenetic and expression analysis of sucrose phosphate synthase isozymes in plants. J Plant Physiol 2007, 164:923-933.

2. Schmalstig JG, Hitz WD: Contributions of sucrose synthase and invertase to the metabolism sucrose in developing leaves. Plant Physiol 1987, 85:407-412.

3. Geigenberger $P$, Stitt M: Sucrose synthase catalyzes a readily reversible reaction in vivo in developing potato tubers and other plant tissues. Planta 1993, 189:329-339.

4. Kleczkowski LA, Kunz S, Wilczynska M: Mechanisms of UDP-Glucose synthesis in plants. Crit Rev Plant Sci 2010, 29:191-203.

5. Martin T, Frommer WB, Salanoubat M, Willmitzer L: Expression of an Arabidopsis sucrose synthase gene indicates a role in metabolization of sucrose both during phloem loading and in sink organs. Plant J 1993, 4:367-377.

6. Coleman HD, Yan J, Mansfield SD: Sucrose synthase affects carbon partitioning to increase cellulose production and altered cell wall ultrastructure. Proc Natl Acad Sci USA 2009, 106:3118-13123.

7. Haigler $\mathrm{CH}$, Ivanova-Datcheva M, Hogan PS, Salnikov W, Hwang S, Martin K, Delmer DP: Carbon partitioning to cellulose synthesis. Plant Mol Biol 2001, 47:29-51.

8. Ruan YL, Llewellyn DJ, Liu Q, Xu SM, Wu LM, Wang L, Furbank RT: Expression of sucrose synthase in the developing endosperm is essential for early seed development in cotton. Funct Plant Biol 2008, 35:382-393.

9. Fu H, Park WD: Sink- and vascular- associated sucrose synthase functions are encoded by different gene classes in potato. Plant Cell 1995, 7:1369-1385.

10. Zrenner R, Salanoubat M, Willmitzer L, Sonnewald U: Evidence of the crucial role of sucrose synthase for sink strength using transgenic potato plants (Solanum tuberosum L.). Plant J 1995, 7:97-107.

11. Chourey PS, Taliercio EW, Carlson SJ, Ruan YL: Genetic evidence that the two isozymes of sucrose synthase present in developing maize endosperm are critical, one for cell wall integrity and the other for starch biosynthesis. Mol Gen Genet 1998, 259:88-96. 
12. Tang $G Q$, Sturm $A$ : Antisense repression of sucrose synthase in carrot affect growth rather than sucrose partitioning. Plant Mol Biol 1999, 41:465-479

13. Barratt DHP, Barber L, Kruger NJ, Smith AM, Wang TL, Martin C: Multiple, distinct isoforms of sucrose synthase in pea. Plant Physiol 2001, 127:655664.

14. Nolte KD, Hendrix DL, Radin JW, Koch KE: Sucrose synthase localization during initiation of seed development and trichome differentiation in cotton ovules. Plant Physiol 1995, 109:1285-1293.

15. Albrecht $G$, Mustroph A: Localization of sucrose synthase in wheat roots: Increased in situ activity of sucrose synthase correlates with cell wall thickening by cellulose deposition under hypoxia. Planta 2003, 217:252260.

16. Fujii S, Hayashi T, Mizuno K: Sucrose synthase is an integral component of the cellulose synthesis machinery. Plant Cell Physiol 2010, 51:294-301.

17. Sun J, Loboda T, Sung S-JS, Black CCJ: Sucrose synthase in wild tomato, Lycopersicon chmielewskii, and tomato fruit sink strength. Plant Physiol 1992, 98:1163-1169.

18. Klotz KL, Finger FL, Shelver WL: Characterization of two sucrose synthase isoforms in sugarbeet root. Plant Physiol Biochem 2003, 41:107-115.

19. Harada T, Satoh S, Yoshioka T, Ishizawa K: Expression of sucrose synthase genes involved in enhanced elongation of pondweed (Potamogeton distinctus) Turions under Anoxia. Ann Bot 2005, 96:683-692.

20. Bieniawska Z, Barratt DHP, Garlick AP, Thole V, Kruger NJ, Martin C, Zrenner $\mathrm{R}$, Smith AM: Analysis of the sucrose synthase gene family in Arabidopsis. Plant J 2007, 49:810-828.

21. Hohnjec N, PerlickA M, Puhler A, Kuster H: The Medicago truncatula sucrose synthase gene MtSucS1 is activated both in the infected region of root nodules and in the cortex of roots colonized by arbuscular mycorrhizal fungi. Mol Plant Microbe Interact 2003, 16:903-915.

22. Baier MC, Keck M, Gödde V, Niehaus K, Küster H, Hohnjec N: Knockdown of the symbiotic sucrose synthase MtSucS1 affects arbuscule maturation and maintenance in mycorrhizal roots of Medicago truncatula. Plant Physiol 2010, 152:1000-1014.

23. Baud S, Vaultier MN, Rochat C: Structure and expression profile the sucrose synthase multigene family in Arabidopsis. J Exp Bot 2004, 55:397-409.

24. Hirose T, Scofield GN, Terao T: An expression analysis profile for the entire sucrose synthase gene family in rice. Plant Sci 2008, 174:534-543.

25. Horst I, Welham T, Kelly S, Kaneko T, Sato S, Tabata S, Parniske M, Wang TL: Tilling mutants of Lotus japonicus reveal that nitrogen assimilation and fixation can occur in the absence of nodule-enhanced sucrose synthase. Plant Physiol 2007, 144:806-820.

26. Koch KE, Nolte KD, Duke ER, McCarty DR, Avigne WT: Sugar levels modulate differential expression of maize sucrose synthase genes. Plant Cell 1992, 4:59-69.

27. Duncan KA, Hardin SC, Huber SC: The three maize sucrose synthase isoforms differ in distribution, localization, and phosphorylation. Plant Cell Physiol 2006, 47:959-971.

28. Wang AY, Kao MH: Differentially and developmentally regulated expression of the three rice sucrose synthase genes. Plant Cell Physiol 1999, 40:800-807.

29. Komatsu A, Moriguchi T, Koyama K, Omura M, Akihama T: Analysis of sucrose synthase genes in citrus suggests different roles and phylogenetic relationships. J Exp Bot 2002, 53:61-71.

30. Ruan YL: Rapid cell expansion and cellulose synthesis regulated by plasmodesmata and sugar: insights from the single-celled cotton fibre. Funct Plant Biol 2007, 34:1-10.

31. Basra AS, Malik CP: Development of the cotton fiber. Int Rev Cytol 1984, 89:65-113.

32. Lee JJ, Woodward AW, Chen ZJ: Gene Expression Changes and Early Events in Cotton Fibre Development. Ann Bot 2007, 100:1391-1401.

33. Ruan YL, Chourey PS, Delmer PD, Perez-Grau L: The differential expression of sucrose synthase in relation to diverse patterns of carbon partitioning in developing cotton seed. Plant Physiol 1997, 115:375-385.

34. Ruan YL, Llewellyn DJ, Furbank RT: Suppression of sucrose synthase gene expression represses cotton fiber cell initiation, elongation, and seed development. Plant Cell 2003, 15:952-964.

35. Huber SC, Huber JL, Liao PC, Gage DA, McMichael RW Jr, Chourey PS, Hannah LC, Koch K: Phosphorylation of serine-15 of maize leaf sucrose synthase. Plant Physiol 1996, 112:793-802.
36. Hardin SC, Huber SC: Proteinsome activity and the post-translational control of sucrose synthase stability in maize leaves. Plant Physiol Bioch 2004, 42:197-208.

37. Chiu WB, Lin $\mathrm{CH}$, Chang CJ, Hsieh MH, Wang AY: Molecular characterization and expression of four cDNAs encoding sucrose synthase from green bamboo Bambusa oldhamii. New Phytol 2006, 170:53-63.

38. Wang F, Smith AC, Brenner Mark L: Temporal and spatial expression pattern of sucrose synthase during tomato fruit development. Plant Physiol 1994, 104:535-540.

39. Sturm A, Lienhard S, Schatt S, Hardegger M: Tissue-specific expression of two genes for sucrose synthase in carrot (Daucus carota L.). Plant Mol Biol 1999, 39:349-360

40. Carlson SJ, Chourey PS, Helentjaris T, Datta R: Gene expression studies on developing kernels of maize sucrose synthase (SuSy) mutants show evidence for a third SuSy gene. Plant Mol Biol 2002, 49:15-29.

41. Martinez de llarduya O, Vicente-Carbajosa J, Sanchez de la Hoz P Carbonero P: Sucrose synthase genes in barley cDNA cloning of the Ss2 type and tissue-specific expression of Ss1 and Ss2. FEBS Lett 1993, 320:177-181.

42. Klotz KL, Haagenson DM: Wounding, anoxia and cold induce sugarbeet sucrose synthase transcriptional changes that are unrelated to protein expression and activity. J Plant Physiol 2008, 165:423-434.

43. Zhang DQ, Xu BH, Yang XH, Zhang ZY, Li BL: The sucrose synthase gene family in Populus: structure, expression, and evolution. Tree Genet Genomes 2011, 7:443-456.

44. Brill E, van Thournout M, White RG, Llewellyn D, Campbell PM, Engelen S, Ruan YL, Arioli T, Furbank RT: A novel isoform of sucrose synthase is targeted to the cell wall during secondary cell wall synthesis in cotton fibre. Plant Physiol 2011, 157:40-54.

45. Frugoli JA, McPeek MA, Thomas TL, McClung CR: Intron loss and gain during evolution of the catalase gene family in angiosperms. Genetics 1998, 149:355-365.

46. Lecharny A, Boudet N, Gy I, Aubourg S, Kreis M: Introns in, introns out in plant gene families: a genomic approach of the dynamics of gene structure. J Struct Funct Genom 2003, 3:111-116.

47. Tang $H$, Bowers JE, Wang $X$, Ming R, Alam M, Paterson AH: Synteny and collinearity in plant genomes. Science 2008, 320:486-488.

48. Rong J, Bowers JE, Schulze SR, Waghmare VN, Rogers CJ, Pierce GJ, Zhang $\mathrm{H}$, Estill JC, Paterson AH: Comparative genomics of Gossypium and Arabidopsis: unraveling the consequences of both ancient and recent polyploidy. Genome Res 2005, 15:1198-1210.

49. Rong J, Feltus FA, Liu L, Lin L, Paterson AH: Gene copy number evolution during tetraploid cotton radiation. Heredity 2010, 105:463-472.

50. Gu ZL, Steinmetz LM, Gu X, Scharfe C, Davis RW, Li WH: Role of duplicate genes in genetic robustness against null mutations. Nature 2003, 421:6366.

51. Flagel LE, Wendel JF: Gene duplication and evolutionary novelty in plants. New Phytol 2009, 183:557-564

52. Zhu HY, Han XY, Lv JH, Zhao L, Xu XY, Zhang TZ, Guo WZ: Structure, expression differentiation and evolution of duplicated fiber developmental genes in Gossypium barbadense and G. Hirsutum. BMC Plant Biol 2011, 11:40.

53. Ruan MB, Liao WB, Zhang XC, Yu XL, Peng M: Analysis of the cotton sucrose synthase 3 (Sus3) promoter and first intron in transgenic Arabidopsis. Plant Sci 2009, 176:342-351.

54. Ruan YL, Chourey PS: A fibreless seed mutation in cotton is associated with lack of fibre cell initiation in ovule epidermis and alterations in sucrose synthase expression and carbon partitioning in developing seeds. Plant Physiol 1998, 118:399-406.

55. Pang CY, Wang $H$, Pang $Y, X u C$, Jiao $Y$, Qin YM, Western TL, Yu SX, Zhu YX: Comparative proteomics indicates that biosynthesis of pectic precursors is important for cotton fiber and Arabidopsis root hair elongation. $\mathrm{Mol}$ Cell Proteomics 2010, 9:2019-2033.

56. Rong J, Pierce GJ, Waghmare VN, Rogers CJ, Desai A, Chee PW, May OL, Gannaway JR, Wendel JF, Wilkins TA, Paterson AH: Genetic mapping and comparative analysis of seven mutants related to seed fiber development in cotton. Theor App/ Genet 2005, 111:1137-1146.

57. Shi YH, Zhu SW, Mao XZ, Feng JX, Qin YM, Zhang L, Cheng J, Wei LP, Wang $Z Y$, Zhu YX: Transcriptome profiling, molecular biological, and 
physiological studies reveal a major role for ethylene in cotton fiber cell elongation. Plant Cell 2006, 18:651-664.

58. Moore RC, Purugganan MD: The evolutionary dynamics of plant duplicate genes. Curr Opin Plant Biol 2005, 8:122-128.

59. McDowell JM, Huang S, McKinney EC, An YQ, Meagher RB: Structure and evolution of the actin gene family in Arabidopsis thaliana. Genetics 1996, 142:587-602.

60. Li XB, Fan XP, Wang XL, Cai L, Yang WC: The cotton ACTIN1 gene is functionally expressed in fibers and participates in fiber elongation. Plant Cell 2009, 17:859-875.

61. Thompson JD, Gibson TJ, Plewniak F, Jeanmougin F, Higgins DG: The clustal_X windows interface: flexible strategies for multiple sequence alignment aided by quality analysis tools. Nucleic Acids Res 1997, 25:4876-4882

62. Paterson A, Brubaker C, Wendel J: A rapid method for extraction of cotton (Gossypium spp.) genomic DNA suitable for RFLP or PCR analysis. Plant Mol Biol Rep 1993, 11:122-127.

63. Jiang J, Zhang T: Extraction of total RNA in cotton tissues with CTABacidic phenolic method. Cotton Sci 2003, 15:166-167.

doi:10.1186/1471-2229-12-85

Cite this article as: Chen et al:: Analyses of the sucrose synthase gene family in cotton: structure, phylogeny and expression patterns. BMC Plant Biology 2012 12:85.

\section{Submit your next manuscript to BioMed Central and take full advantage of:}

- Convenient online submission

- Thorough peer review

- No space constraints or color figure charges

- Immediate publication on acceptance

- Inclusion in PubMed, CAS, Scopus and Google Scholar

- Research which is freely available for redistribution 